\title{
Teaching Ethics and Leadership with Cases: A Bottom-up Approach
}

\section{Dr. Daniel F. Jennings PE, Texas A\&M University}

Daniel F. Jennings is the Andrew Rader Professor of Industrial Distribution and Program Director of the Master of Industrial Distribution Degree at Texas A\&M University. He received his PhD from Texas A\&M university and is a Registered Professional Engineer. His research focuses on entrepreneurship, ethical dilemmas, and developing a sustainable competitive advantage within industrial distribution channels.

\section{Dr. Bimal P. Nepal, Texas A\&M University}

Dr. Bimal Nepal is an assistant professor in the Industrial Distribution Program at Texas A\&M University. His research interests include integration of supply chain management with new product development decisions, distributor service portfolio optimization, pricing optimization, supply chain risk analysis, lean and six sigma, and large scale optimization. He has authored 30 refereed articles in leading supply chain and operations management journals, and 35 peer reviewed conference proceedings articles in these areas. He has B.S. in ME, and both M.S. and Ph.D. in IE. He is a member of ASEE, INFORMS, and a senior member of IIE. 


\title{
Teaching Ethics and Leadership with Cases: A Bottom-up Approach
}

\begin{abstract}
The issue of ethics in leadership has taken greater importance in the today's business world due to globalization and rapid advancement in information technology which has significantly transformed current business practices. Most universities in the United States (US) now have at least one course that includes ethics or related topics in their undergraduate engineering curricula. However, due to qualitative and abstract nature of the topic, the ethics course does not draw the same level of attention from students compared to other courses like physics and math. In this paper, we propose an innovative way of teaching ethics and leadership topics at the undergraduate level. In particular, the paper presents a case study of a senior level course in ethics and leadership development for an Industrial Distribution program at a major university in the Southwestern US. The course focuses on learning about personal leadership skills within the context of an organization. It examines the role and purpose of ethics in business and presents methods of moral reasoning in order to resolve ethical dilemmas. The paper describes how teaching based on "case study" approach has improved students understanding of the concepts and generated interest in the topic. We also discuss a sample case and overall course planning and execution framework, just in case any other instructor is considering teaching the similar course. Finally, student feedbacks are presented to demonstrate the successful implementation of the proposed teaching method.
\end{abstract}

\section{Introduction}

Although leadership is practiced at all levels in an organization, members of an organization may know very little about the strategy and psychology of leadership. One of the dilemmas for business leaders around the world, the ones with a moral compass, is the question of the applicability of business ethics. The concept of business ethics refers to the unwritten moral code that guides the manner in which business is practiced. Unlike legal requirements that are backed up by the force of law and sanctions, ethical codes are generally not legally required in the sense that there are no lists of sanctions for poor business ethics. However, the issue of corporate responsibility is a practice that business leaders around the world understand to be a necessity, both from the point of good morals, profitability, and from the point of maintaining a good relationship with the community in which the organization is located.

Ethics and leaderships have now become an integral part of engineering undergraduate degree curricula in US engineering schools and are mandated by the accreditation agency like ABET. The importance of ethics has been well recognized by many engineering colleges and universities around the world as they are the ones who produce the next generation of business leaders. Educators such as Bird and Sieber (2005) suggest that there are a number of reasons that 
can justify the teaching ethics to undergraduate (UG) engineering students and argue that the following are the key reasons for necessity of teaching ethics at UG level: (a) many public policy decisions are based on scientific reasoning and findings; (b) engineers are also part of society and they work to improve the lives of human beings; and (c) there could be huge personal interest and "conflicting professional interests" in a number of projects in which an engineer is involved. Colby and Sullivan (2008), sponsored by the Carnegie Foundation, conducted a comparative analysis of ethics courses taught at several US business schools in which the case method was utilized. Colby and Sullivan (2008) reported that that in almost all schools they studied, the primary goal of the ethics course was to teach the professional codes of ethics, which include: public safety, health and welfare, and protection of environment; loyalty to both employer and customers; fairness; intellectual properties of others; conflicts of interest; and discrimination and unfair competition. Chan et al. (2012) describe entrepreneurship, professionalism, and leadership as three key aspects of today's engineering careers which are increasingly becoming "boundaryless".

Leadership education has also garnered immense attraction recently in engineering curricula across the world as today's globalized market presents the students with great technical leadership challenges (Khattak, $\mathrm{Ku}$, and Goh, 2012). Interestingly, leadership class examples found in the literature varies in both scope and learning framework. Some programs are designed as a certificate in leadership by offering multiple courses whereas others are associated with laboratory projects, senior design projects, machine safety, or similar environment where students have to deal with multiple aspects including team work, human-machine interactions, etc. For example, Wu (2008) presents a case study of teaching safety leadership at Taiwanese universities. A prior study shows that universities in the Europe and Australia also follow the project based approach in teaching leadership to engineering students ((Khattak et al., 2012). Penn State's (USA) Engineering Leadership Development Minor (EDLM) is a slightly different model than any project based leadership model used in laboratories. The EDLM Model requires students to take multiple courses in leadership focusing on core leadership qualities, global leadership qualities, and $21^{\text {st }}$ century leadership qualities (Schuhmann, 2011). Similarly, Babucia, Craig, and Connor (2012) discuss MIT satellite development program projects which provide students with the leadership education through a project based approach. The MIT program is a three-term class focusing on engineering topics and developed for implementation at satellite locations. Babucia et al (2012) report their model has been adopted around the world.

Similar to leadership, there are various pedagogical models available in the literature with respect to teaching ethics in UG classes. Bird and Sieber (2005) suggest that ethics in science and engineering cannot be taught simply through observational examples and argue that learning by observation requires interpretation which can create confusion and misunderstanding. Billington (2006) suggests teaching ethics by incorporating historical examples and cases and making the class "visual" so students can better understand ethical scenarios. Further, Conlon 
and Zandvoort (2011) suggest that ethics courses should focus on the role of organizational culture and societal norms rather than on the role of a single individual.

In the present paper, we propose a comprehensive approach for teaching an ethics and leadership course. More specifically, we utilize real world cases in our course and unlike the approach of using observational examples and a top-down approach (Bird and Sieber, 2005), we propose to engage students in actually analyzing case studies (a bottom-up approach) by using scientific methods and to have the students make recommendations by considering the broader impact of the culture of organization included in the case analysis.

The remainder of our paper is organized into the following three sections. In the first section, course objectives, learning outcomes and assessment methods are explained to the participating students. After that, a sample case study is utilized to demonstrate our teaching approach. Lastly, we conclude our paper with some remarks on student and industry feedback on the course.

\section{Ethics and Leadership Course in Industrial Distribution Program}

As mentioned earlier, this paper presents a case study of a senior level course in ethics and leadership development for an Industrial Distribution program at a major university in the Southwestern US. In addition to lectures on various ethical concepts and models together with lectures on and leadership theories, the course consists of several real world industry cases. Students are required to perform analysis on those cases and answer several questions pertaining to leadership and ethical issues surrounding different business situations. The actual learning takes place through these cases. The course is designed in such a way that students are highly engaged in class activities and performing an in-depth case analysis. In the following paragraphs, we describe the course objectives, learning outcomes, and assessment methods of student learning.

\section{Course Objectives}

The course focuses on learning about personal leadership skills within the context of an organization. It examines the role and purpose of ethics in business and presents methods of moral reasoning in order to resolve ethical dilemmas. The course is divided into two parts. The first part focuses on leadership theories, styles, factors affecting the leadership styles, and nature of business ethics. The second part of this course focuses on the preparation of both a written and oral leadership project that applies the concepts from the first part of the course to either a supplier or distributor firm in Industrial Distribution.

\section{Learning Outcomes}

Upon successful completion of this course, students are able to:(i) develop the understanding of difference between leadership and management; (ii) develop the understanding of different leadership theories and styles; (iii) ability to work in a team environment and apply simple 
leadership theories and change management skills in a business management context; (iv) able to understand the impact of various factors on leadership style of a leader; (v) analyze a business situation in the context of a complex ethical and leadership dilemma by applying the concepts such as Kohlberg's moral development (Kohlberg, 1984), nature of business ethics, and leadership theories such as Narcissism and Hubris; and (vi) ability to communicate effectively both orally and through written reports.

\section{Assessment of Learning}

In this course, the student learning is assessed by using multiple measures. The key components of learning assessment are as follows:

Written Leadership Project: This is a group assignment involving three to four students depending upon the class size. This is a key component of a student overall grade in the course. This assesses students' ability to communicate in writing. Peer evaluations are used to assign individual grades. Each member of each group is required to complete a peer evaluation form which is provided by the instructor in the course packet.

Oral Presentation of the Written Leadership Project: Each group is required to make an in class-oral presentation of their written project. All members of the group are required to participate. The class participation is highly encouraged in the whole presentation process. For example, each class member and the course instructor jointly assign a grade to the oral presentation for each of the individual presenters.

Guest Speaker Quizzes and Eureka Exercise: Several Guest Speakers from industry are invited to class. Usually these speakers are very high level executives (vice presidents, presidents or CEOs) of distribution firms who would share their leadership philosophy, styles, and experience with the class. Following the presentation of each Guest Speaker, a short written quiz is administered. In order to motivate students to come to class, speaker quiz grades is neither dropped nor allowed for make-up quiz.

In addition to speaker quiz, each student is required to prepare a written report (3-6 pages) of any "concept" presented by a Guest Speaker. Students are encouraged to be creative in preparing this report. This exercise is termed as "Eureka Exercise" and can be "turned-in" at any time before the end of the semester.

Case Exam: A take-home case exam is administered in the course. Students may work in their "regular" group or by themselves. Since this course is more focused on the analysis of cases, no traditional topic based final exam is required.

Daily Quizzes: A number of Daily Quizzes are administered throughout the semester which may occur at the beginning, ending or during the class. These quizzes cover the case, reading 
assignments, lecture material, and class discussions. These daily quizzes are designed to provide students with an additional opportunity to demonstrate their mastery of the topics that are being covered beyond the major exams. Students are allowed to drop the grade of any two daily quizzes. NO make-ups are given for missed daily quizzes.

Written Case Analysis: Working with their regular group, students will prepare written answers to end-of-case questions for four cases: Carolyn Shelton, Metro Distributors, ExI Corporation and Dilemma in Zapata. The case articles are questions are provided to students in the course packet. In this paper, we discuss ExI Corporation as a sample case study. All the four cases are prepared by the instructor and are based on the real world company.

Homework Assignments: A number of homework assignments (both individual and group) are included in this course as follows:

a) There are three individual assignments based on three articles published in major newspapers like New York Times.

b) There are four group assignments that include analysis of following cases:

- Antecedents and Consequences of Hubris

- Distribution Value Activities Assignment

- Why Fair Bosses Fall Behind

- Was Steve Jobs An Effective Leader

\section{ExI Corporation: A Sample Case Study Used in the Course}

In this section, we discuss the case synopsis, learning objectives/outcomes, assignment questions, and results along with important leadership insights as follows.

Case synopsis: In order to perform needed routine maintenance and to replace malfunctioning equipment, large manufacturing firms, power plants, and firms in different process industries schedule turnarounds. During the turnaround, specific operating equipment is shut down, the needed repairs and replacements are made, the equipment is then restarted and becomes operational. A major task in restarting the operating equipment is to ensure that all electrical systems are properly calibrated to ensure that electrical power quality is attained. Portable electrical testing equipment has been developed that will properly and safely perform the necessary tests. Because the test equipment is very expensive, end-users seek ways to avoid purchasing or leasing such equipment. Accordingly, a number of businesses have developed in which these businesses acquire testing equipment from a particular manufacturer and will then rent that equipment to an end-user for a short-time period. These end-users include the preceding large manufacturing firms, power plants, and firms in different process industries as well as utilities and commercial construction firms. 
$\mathrm{E}_{\mathrm{X}} \mathrm{I}$, an $\mathrm{S}$ Corporation located in Grand Prairie, Texas, is such a company. In addition to renting a variety of test equipment to the operating end-users, $E_{X} I$ also provides qualified engineering technicians that will operate the test equipment during a turnaround. $\mathrm{E}_{\mathrm{X}} \mathrm{I}$ was started by two individuals, Kenneth Davis who invested \$1.5 million in the venture and Ronald Maak who made no financial investment in the start-up. A the time of $E_{X} I$ 's start-up, six-years ago, Kenneth and Ronald agreed that (1) Ronald would manage $E_{X} I$ on a day -to-day basis and that Kenneth would be involved in "strategic decisions" (2) after achieving a series of mutually agreed upon milestones, Ronald would receive a percentage ownership of $E_{X} I$ up to $49 \%$ and (3) once Ronald achieved a $49 \%$ ownership of $E_{X} I$, Kenneth would sell his $51 \%$ percent ownership portion of $E_{X} I$ to Ronald. However, at the time the ownership agreement was developed between Ronald and Kenneth, nothing was specified on how much Ronald would pay Kenneth for Kenneth's portion of the company, nor was any methodology agreed upon on how the value of Kenneth's ownership would be determined.

$E_{X} I$ has a Board of Directors composed of five individuals: Kenneth Davis and his wife Susan; Ronald Maak and his wife Portia, and Samuel Weinberg, an attorney living in Houston, Texas. Also, $E_{X} I$ has only two shareholders, Ronald and Kenneth. Further, Kenneth and Ronald have elected to have $E_{X} I$ 's net income to be retained by the corporation rather than being distributed to themselves. (Such a provision is allowed in " $\mathrm{S}$ " Corporations.). As a legal requirement, $\mathrm{E}_{\mathrm{X}} \mathrm{I}$ has a Corporate Charter which contains certain By-Laws. One such By-Law states that that any funds that are entered into $E_{X} I$ stockholder's equity account (common stock, retained earnings, and undistributed income) are to be used for the operation of $\mathrm{E}_{X} \mathrm{I}$. Neither Kenneth nor Ronald has any claim on those funds. EXI's By-Laws can be changed by a majority vote of the Board of Directors. At the time of the case, $E_{X} I$ 's stock equity is $\$ 2,726,000$.

Kenneth became the Chief Executive Officer and Board Chairman of $E_{X} I$. However, Kenneth was involved in managing another company, Thor Services, which was not a competitor of $E_{X} I$. Ronald became the Chief Operating Officer of $\mathrm{E}_{X} \mathrm{I}$ and actually managed the business. In managing $\mathrm{E}_{\mathrm{X}} \mathrm{I}$, Ronald has (1) employed his wife, Portia, to manage the finances and administrative functions; (2) hired a long-time friend, Jason Henry to manage sales; (3) worked with Portia and Jason to develop a system of operating procedures: (4) developed and implemented a sales program; (5) and hired additional employees. At the time of case, excluding Kenneth, thirty-four individuals were full-time $E_{X} I$ employees.

As stated earlier, at the time of the case $\mathrm{E}_{\mathrm{X}} \mathrm{I}$ had been in operation for six years. Following is a listing of certain financial accomplishments for the first six years of EXI's existence:

- Revenues increased from zero to $\$ 9.4$ million;

- Gross Margin increased from 57\% to 61\%;

- Operating Income as a percentage of sales increased from 5\% to 15\%; 
- In actual dollar amounts, operating income increased from $\$ 473,000$ to $\$ 3,159,000$ nearly a six fold increase;

- EBITDA $^{1}$ has doubled during EXI's six years of existence.

Clearly, an analysis of EXI's financial statements indicates an extraordinary performance by Ronald Maak and his team at $E_{X} I$.

Within the case, Roland informs Kenneth that he [Ronald) wants to acquire the remaining 51\% ownership of $E_{X} I$ and asks Kenneth to indicate a purchase price. Kenneth does not respond. Later, Ronald informs Kenneth that he [Ronald] will pay Kenneth one million dollars for the $51 \%$ ownership. Kenneth still does not respond. Ronald then requests a personal meeting with Kenneth to discuss a variety of issues including his [Ronald's] desire to obtain the remaining shares of $E_{X} I$. Kenneth agrees to the meeting and a date for the meeting is agreed upon. However, at a different date, Kenneth accompanied by John Nelson, owner of a management consulting firm, makes an unscheduled visit to $E_{X} I$. During that unscheduled meeting, Kenneth reviews a number of issues which he believes should be addressed by Ronald and Kenneth refuses to discuss Ronald's one million dollar offer to acquire the 51\% remaining ownership. Kenneth further informs Ronald that he [Kenneth] has to leave the $E_{X} I$ site to attend to business activities for his other company (Thor Services). John Nelson is to remain on the $E_{X} I$ site and Ronald is to provide answers to any questions that Nelson might have pertaining to $E_{X} I$. Further, Kenneth informs John Nelson that he [Kenneth] believes that $E_{x} I$ can be sold to a larger company provided that $\mathrm{E}_{\mathrm{x}} \mathrm{I}$ 's financial performance is maintained.

Two weeks after the John Nelson -Ronald-Kenneth- meeting at $E_{X} I$, Kenneth becomes aware of the following:

- After Kenneth refused to accept Ronald's offer to purchase the $51 \%$ ownership of $\mathrm{E}_{X} \mathrm{I}$ for one million dollars, Ronald has started another company, Willitrent, to compete with $\mathrm{E}_{X} \mathrm{I}$;

- Portia, Ronald's wife, and Sales Manager, Jason Henry, have decided to leave $\mathrm{E}_{X} \mathrm{I}$ and to work for Willitrent;

- Several of $E_{X} I$ 's major customers have switched their business from $E_{X} I$ to Willitrent;

- Important documents pertaining to $E_{X} I$ 's customers are missing and presumed to have been taken by Jason Henry.

Kenneth used an accounting firm to conduct an audit of $E_{X} I$ 's assets and was made aware that during the past two weeks in question; Ronald had taken $\$ 600,000$ in testing equipment and

\footnotetext{
${ }^{1}$ EBITDA is an acronym for the term "Earnings before Interest, Depreciation, and Amortization" and is an approximate measure of a company's operating cash flow. Because the distortions associated with accounting and financing effects on company earnings do not factor into EBITDA, it is widely used to compare the financial performance of companies within and across industries.
} 
$\$ 400,000$ in cash from $E_{X} I$. Kenneth then contacted Attorney Sam Weinberg to file an injunction to stop Willitrent and Ronald to stop them from unfairly competing against $E_{X} I$ and to consider any other legal actions that is feasible.

Learning objectives and outcomes: The present case has been designed to focus on the unethical behavior of two partners in a business after one of the partners has been rebuffed in an attempt to buy-out his business partner. Outcomes of the present case include:

- Developing a business start-up;

- Valuing a business;

- Understanding income statements, balance sheets, and cash flow statements;

- Becoming aware of the importance of partnership agreements;

- Dealing with senior management conflicts

Assignment questions: It is important to understand the age and educational level of the two protagonists, Kenneth Davis and Ronald Maak, before the discussion of the case questions begin. Such an understanding will provide some insights into the behaviors exhibited by Kenneth and Ronald during the case.

\section{Questions}

1. Using the financial information presented in Appendices 3, 4, and 5 of the case, calculate a fair market value of $E_{X} I$.

2. Compare the fair market value calculated in Question \#1 with the \$1 million dollars that Ronald offered to Kenneth to purchase the $51 \%$ ownership held by Kenneth.

3. The meeting between Kenneth and Ronald in which Kenneth explained that John Nelson would be involved in EXI's business provoked a confrontation between Kenneth and Ronald. Discuss how that confrontation could have been avoided.

4. At the end of the present case, Kenneth considered a variety of options. He could:

(a) Liquidate $\mathrm{E}_{\mathrm{X}} \mathrm{I}$ as quickly as possible;

(b) Recruit individuals with experience in $\mathrm{E}_{X} \mathrm{I}$ 's line of business including those individuals having an understanding of $\mathrm{E}_{\mathrm{X}} \mathrm{I}$ 's suppliers and customers to manage $\mathrm{E}_{\mathrm{X}} \mathrm{I}$ and take it to the next level;

(c) Recruit adaptable, intelligent people whom Kenneth could trust to manage $E_{X} I$ and take it to the next level;

(d) Approach Ronald and inform of the knowledge that $\$ 1$ million in assets have been taken from $\mathrm{E}_{X} \mathrm{I}$. Advise him of the impending legal action and offer to negotiate a price to sell his $51 \%$ share to $\mathrm{E}_{\mathrm{X}} \mathrm{I}$ to Ronald;

(e) Approach Ronald and inform of the knowledge that $\$ 1$ million in assets have been taken from $E_{X} I$. Advise him of the impending legal action and offer to acquire Ronald's $49 \%$ share of $\mathrm{E}_{\mathrm{X}} \mathrm{I}$;

(f) Attempt to sell $\mathrm{E}_{\mathrm{x}} \mathrm{I}$ to a larger company. 
Which of the preceding six options should Kenneth adopt in dealing with the present situation? Discuss the advantages and disadvantages of the selected option.

5. Should Kenneth consider an option that is not described in Question \#4? Discuss the advantages and disadvantages of such an option.

6. How ethical has Kenneth been in his dealings with Ronald? Explain.

7. How ethical has Ronald been in his dealing with Kenneth? Explain

Results and discussion: Determining the age and education of Kenneth and Ronald.

Kenneth's Age

\begin{tabular}{|l|c|c|}
\hline Event & Time Involved & Age \\
\hline Graduation from Naval Academy & & 21 \\
\hline Service in U.S. Navy & 10 years & \\
\hline Operating Thor Services before starting $\mathrm{E}_{\mathrm{X}} \mathrm{I}$ & 8 years & \\
\hline Involvement with $\mathrm{E}_{\mathrm{X}} \mathrm{I}$. & 7 years & \\
\hline Time of the case & 25 years (total) & 46 \\
\hline
\end{tabular}

Ronald's Age

\begin{tabular}{|l|c|c|}
\hline Event & Time Involved & Age \\
\hline Enlisted in U.S. Air Force & & 16 \\
\hline Service in U.S. Air Force & 8 years & \\
\hline Employed by GE & 4 years & \\
\hline Involvement with $E_{X}$ I. & 7 years & \\
\hline Time of the case & 19 years (total) & 35 \\
\hline
\end{tabular}

\section{Kenneth's Education}

BS with high honors in Electrical Engineering from the Naval Academy; MS in Nuclear Engineering from Massachusetts Institute of Technology (MIT).

\section{Ronald's Education}

High school diploma (GED) while serving in the Air Force

\section{Stimulating the age-education discussion}

In order to stimulate a discussion among case participants regarding age and education differences, the case instructor can ask the case participants if they have developed any insights from the present case. For example, during a conversation between Kenneth and Ronald that occurred in the case, Kenneth states: "Ronald, I don't know many high school graduates who are earning an annual seven figure income and have the degree of autonomy in running a business that you have in managing $E_{X} I$." Ronald replied: "Why do you always bring up my lack of a college education whenever we discuss $E_{X} I$ 's future? I know that I just have a high school 
education. I know that I didn't graduate from the Naval Academy and I don't have a MS in Engineering with great honors that you have."

The case instructor should push the case participants to identify specific situations in which any insecurity exists between Kenneth and Ronald based on age and education.

Question \#1: Case participants may not be aware of approaches used to calculate the value of a business firm. Exhibit 1 presents such an analysis and will allow the class participants to answer Question \#1. The case instructor should note that determining the value of a business is a difficult process.

Six approaches are described which yield different values when calculated. Using Exhibit 1 of the Case entitled "How To Value a Business" Approach \#3, Income method yields a value of $\$ 8,172,000$ which is the highest value.

Question \#2: If we presume that the fair market value of $E_{X} I$ is $\$ 8,172,000$ [from Question \#1), then Kenneth's $51 \%$ share has a financial value of: $(0.51)(\$ 8,172,000)=\$ 4,167,720$. By inspection, the financial value of $\$ 4,167,720$ is considerably higher than the $\$ 1$ million offered by Ronald. Interestingly, the market values calculate by case participants during the prior semester ranged from $\$ 4,100,000$ to $\$ 9,350,000$. Thus, using any of the preceding market values, one can argue that the $\$ 1$ million dollars offered by Ronald does not accurately depict Kenneth's $51 \%$ of $E_{X} I$.

Question \#3: One class participant provided the following comments regarding the meeting attended by Kenneth, Ronald and John Nelson:

"We don't really know how much communication has occurred between Kenneth and Ronald regarding how $E_{x} I$ has been managed. We know from the Case that Kenneth invested \$1.5 million in $E_{x} I$ and was heavily involved in the start-up. After that, one can conjecture that Kenneth probably stayed out of the picture and allowed Ronald to run the business.

One can appreciate Kenneth's concern that Ronald, Portia, and Jason Henry are spread pretty thin at the present time. However, it was a bad move on Kenneth's part to show up at the $\mathrm{E}_{\mathrm{x}} \mathrm{I}$ facility with John Nelson in tow and then to advise Ronald of Nelson's proposed role. An interesting question-was Kenneth looking for a fight? Was he trying to provoke Ronald into leaving $E_{x} I$ ? In fact, Kenneth believes that Ronald, Portia, and Jason Henry have too much control over $\mathrm{E}_{\mathrm{x}} \mathrm{I}$. At any rate, Kenneth should have done things differently. For example, he might have asked Ronald what assistance he needs in order to continue to grow the business. Get Ronald's input and suggestions. Later, Kenneth might offer to bring in someone such as Nelson. 
If Ronald agrees, then Kenneth could say-I know someone who might come to $\mathrm{E}_{\mathrm{x}} \mathrm{I}$ - and then bring Nelson into the picture.

However, several class participants argued that it was appropriate for Kenneth to "show-up" unannounced with John Nelson and to question Ronald about how $\mathrm{E}_{\mathrm{x}} \mathrm{I}$ is being managed.

Question \#4: No former case participant selected option (a), (d), (e) or (f). Former case participants indicated the reason for not selecting option (a) is that $E_{x} I$ has too much potential to be liquidated. Those former case participants who rejected options (d) and (e) argued that Kenneth should not approach Ronald about anything associated with $\mathrm{E}_{\mathrm{x}} \mathrm{I}$ because of Ronald's prior actions. Also, those former case participants who rejected option (f) indicated that the present problems faced by $E_{x} I$ would drive away potential companies interested in $E_{x} I$ or significantly lower the acquisition price.

Former case participants were almost equally divided between options (b) and (c). Following is the discussion of the advantages and disadvantages for the two selected options (b) and (c)

Advantages for selecting option (b):

Former case participants believed that newly recruited individuals should have knowledge of $E_{\mathrm{x}} \mathrm{I}$ 's suppliers and customers because of the technical requirements of $\mathrm{E}_{\mathrm{x}} \mathrm{I}$ 's business. Several former case participants provided the following comment: "The Case stated that Kenneth believes that $\mathrm{E}_{\mathrm{x}} \mathrm{I}$ 's customers operate in an industry that is highly driven by relationships. The industry has a low tolerance for mistakes."

Disadvantages for selecting option (b):

Former case participants indicated that Ronald worked extremely long hours in making $\mathrm{E}_{\mathrm{x}} \mathrm{I}$ a success and argued that these individuals will not do so unless they are highly compensated. Also Kenneth practiced a "hands-off" managerial style with Ronald. Kenneth was not a micromanager. Such a managerial style may not work well in the future.

\section{Advantages for selecting option (c):}

Former case participants indicated that because of his involvement with his other business, Thor Services, Kenneth doesn't have the time to spend in directing newly recruited individuals. Kenneth needs individuals that can adapt, are trustful and intelligent and can operate with little direction.

\section{Disadvantages for selecting option (c):}

Former case participants expressed Kenneth's belief that $\mathrm{E}_{\mathrm{x}} \mathrm{I}$ 's customers operate in an industry that is highly driven by relationships. It will be difficult for individuals without such a relationship to be successful. 
Later, during the case discussion, one case participant changed their recommendation to liquidation "as soon as possible." The advantage cited by that participant in doing so is that "there is nobody really left to recruit out there that knows about $\mathrm{E}_{\mathrm{X}} \mathrm{I}$ 's business... Also by the time Kenneth can recruit new employees, Willitrent will have acquired most of ExI's customers and Kenneth will have "burned" through most of ExI's shareholder's equity. Also, Kenneth has doubled his investment in $\mathrm{E}_{\mathrm{X}} \mathrm{I}$ and should receive additional money from the liquidation.

Question \#5: New Option 1: Several former case participants indicated that the Case suggests ExI needs two additional employees. "One of these individuals needed to have the capabilities to be the Chief Operating Officer who could manage the day-to-day operation of $E_{x} I$. The other was a person with a familiarity of $E_{x} I$ 's line of business who could assume the position of Sales Manager." Accordingly, those former case participants suggested that Kenneth should focus on specific needs of $\mathrm{E}_{\mathrm{X}} \mathrm{I}$ and recruit individuals having the capabilities to fulfill those needs. Accordingly, this new option is: The Chief Operating Officer could be recruited from outside the industry while the Sales Manager should have industry experience.

\section{Advantages of new option 1:}

Former case participants stated that the needs of $E_{x} I$ would be fulfilled by the addition of two individuals. The Chief Operating Officer doesn't necessarily need the required industry experience but needs to be a "strong" administrator. On the other hand, the Sales Manager does need industry experience.

\section{Disadvantages of the new option 1:}

Interestingly, former participants who selected the new option indicated that there were no disadvantages associated with this option.

New Option 2: Several case participants indicated that a new option is that Kenneth should "try to make peace with Ronald and have him stay on as an $E_{x} I$ employee. A strong argument can be made that given the facts of the situation; it will be extremely difficult for Kenneth and Ronald to maintain any type of future working arrangement.

Question \#6: Nearly two-thirds of the former case participants indicated that Kenneth had acted ethically in his relationships with Ronald. Some discussion occurred about Kenneth's lack of involvement in $\mathrm{E}_{\mathrm{X}} \mathrm{I}$ 's day-to-day operations. However, most former case participants indicated that such behavior is not unethical and is probably Kenneth's management style. During an inclass discussion, one former case participant indicated that Kenneth has demonstrated an interest in the day-to-day operations of $\mathrm{E}_{\mathrm{x}} \mathrm{I}$ in that he had questioned Ronald about $\mathrm{E}_{\mathrm{x}} \mathrm{I}$ 's declining gross margins. 
The remaining one-third of the former case participants indicated that Kenneth acted unethically because he engaged in the following questionable behaviors: (a) failing to respond to Ronald's offer of $\$ 1$ million dollars to purchase $51 \%$ of $E_{x} I$; (b) not having a procedure on how the value of $51 \%$ of $\mathrm{E}_{\mathrm{x}} \mathrm{I}$ would be calculated; (c) not informing Ronald of his [Kenneth's] intent to sell $\mathrm{E}_{\mathrm{x}} \mathrm{I}$ to a larger company within a few years; (d) not clearly explaining to Ronald the language included in $\mathrm{E}_{\mathrm{x}} \mathrm{I}$ 's By-Laws; (e) arranging the composition of $\mathrm{E}_{\mathrm{x}} \mathrm{I}$ 's Board of Directors to include three of the five Board Members who would support Kenneth's recommendations; and (f) involving John Nelson in the day-to-day operations of $E_{x} I$ without notifying Ronald of such an action plan.

Question \#7: All former case participants indicated a strong belief that Ronald had been very unethical in his dealings with Kenneth. Following is a response from a former case participant. "Ronald had a great idea about starting a business. He met Kenneth who was an entrepreneur with technical skills. Ronald discussed his idea with Kenneth and $\mathrm{E}_{\mathrm{x}} \mathrm{I}$ was started. During the start-up, Kenneth invested $\$ 1.5$ million in $E_{x} I$ while Ronald didn't contribute any funding. Kenneth was very helpful in getting $\mathrm{E}_{\mathrm{x}} \mathrm{I}$ started. In fact, Kenneth did the majority of the planning and execution. Kenneth and Ronald had an arrangement in which Ronald could acquire 100\% ownership of $E_{x} I$. Ronald offered Kenneth $\$ 1$ million for his share of $E_{x} I$. However, Kenneth never responded to Ronald's $\$ 1$ million offer. That failed response led to a confrontational meeting between Ronald and Kenneth. Ronald didn't like it when Kenneth began questioning the amount of control that Ronald, Portia and Jason had in managing $\mathrm{E}_{\mathrm{x}} \mathrm{I}$. Ronald used $\mathrm{E}_{\mathrm{x}} \mathrm{I}$ 's equipment and cash to start a competing company, Willitrent, and is trying to lure additional customers to do so. Also, Ronald took confidential information from $\mathrm{E}_{\mathrm{x}} \mathrm{I}$ 's premises and valuable documents are now missing. Also, Ronald is recruiting key employees to leave $E_{x} I$ and work for Willitrent. Finally, taking $\$ 1$ million in $\mathrm{E}_{\mathrm{X}} \mathrm{I}$ 's cash and assets to start a competitive company is another example Ronald's unethical behavior.

\section{Feedback from students and industry partners:}

Student evaluations: The overall student evaluations for seventy students who were enrolled in the prior semester were 4.81/5.0. Written comments from the students indicated the following: The most positive aspects of the course: Learning about ethical dilemmas in the workplace based on real-world experiences.

What qualities did you like most about your instructor: Used well written case studies. In-class case discussions were well conducted and contributed to the learning process.

Comments from Industry partners: Senior managers of $\mathrm{E}_{\mathrm{x}} \mathrm{I}$ were present during the case discussion but did not participate in the actual in-class discussion. At the conclusion of the class, those managers informed the students of certain events that have occurred at $\mathrm{E}_{\mathrm{X}} \mathrm{I}$ since the writing of the present case. Also, the senior managers indicated they were impressed on the depth of discussion that had occurred. 


\section{Conclusions}

Today's business leaders are faced with constant leadership challenges due to globalized marketplace, advances in information technology, wide spread use of social media, and ease of access to information. As a result, ethics and leadership education has taken greater importance in college education in recent years. However, teaching approach to these courses varies across discipline depending upon the nature of academic program and teaching style of the instructors. This paper has presented a comprehensive approach for teaching an ethics and leadership course in an industrial distribution program. The paper has proposed a bottom up approach in teaching the course by utilizing real world cases thereby engaging students in actual analysis of cases. A sample case was presented to demonstrate the proposed teaching approach. The example case included the learning objectives, assignment questions, and different decision options that a student (or leader) could undertake in a given business situation. The case also provided solutions along with in-depth insights of real world ethical situations in which a business leader has to exercise his/her leadership skills to make the best possible decision. Both the content and teaching approach have been appreciated by students and industry partners who usually hire the graduate of the industrial distribution program this paper has addressed.

\section{References}

1. Babuscia, A., Criag, J.L., Connor, J.A. (2012). Teaching practical leadership in MIT satellite development class: CASTAR and Exoplanet projects, Acta Astronautica, Vol. (77), 138-148.

2. Billington, D.P. (2006). Teaching ethics in engineering education through historical analysis, Science and Engineering Ethics, Vol. 12, 205-222.

3. Bird, S.J., Sieber, J.E. (2005). Teaching ethics in science engineering: effective online education, Science and Engineering Ethics, Vol. 11, 323-328.

4. Chan, K.Y., Ho, M, R., Chernyshenko, O. S., Bedford, O., Uy, M.A., Gomulya, D., Sam, Y.L., Phan, W. M. J. (2012). Journal of Vocational Behavior, Vol. 81, 73-88.

5. Colby, A., Sullivan, W. M. (2008). Ethics teaching in undergraduate engineering education, Journal of Engineering Education, July, 327-338.

6. Conlon, E., Zandvoort, H. (2011). Broadening ethics teaching in engineering: beyond the individualistic approach, Science and Engineering Ethics, Vol. 17, 217-232.

7. Khattak, H., Ku, H., Goh, S. (2012). Courses for teaching leadership capacity in professional engineering degrees in Australia and Europe, European Journal of Engineering Education, Vol. 37(3), 279-296.

8. Kohlberg, L. (1984). Essays on moral development: The psychology of moral development: Moral stages, their nature and validity, Vol. 2.

9. Schuhmann, R.J. (2011). Engineering leadership education-the search for definition and curricular approach, Journal of STEM Education, Vol. 11(3\&4), 61-69.

10. Wu, T-C. (2008). Safety leadership in the teaching laboratories of electrical and electronic engineering departments at Taiwanese Universities, Journal of Safety Research, Vol. 39, 599-607. 